\title{
High Speed Photography of Laser Induced Forward Transfer (LIFT) of Single and Double-layered Transfer Layers for Single Cell Transfer
}

\author{
D. Riester, J. Budde ${ }^{1}$, C. Gach ${ }^{1}$, A. Gillner ${ }^{1,2}$, M. Wehner ${ }^{1}$ \\ ${ }^{1}$ Fraunhofer Institute for Laser Technology, Steinbachstr. 15, 52074 Aachen, Germany \\ ${ }^{2}$ Chair of Laser Technology LLT, Steinbachstr. 15, 52074 Aachen, Germany
}

dominik.riester@ilt.fraunhofer.de

\begin{abstract}
Bioprinting technologies allow the construction of tissue-like structures from different cell populations. Fundamental research on the influence of the cell micro-environment requires printing of single cells in specific patterns on a microscopic scale. Single cell printing of living cells has been performed by nozzle based techniques or micro-pipetting, and laser-induced forward transfer (LIFT) has turned out to enable a virtually contact-free printing process. In this work the LIFT process from gelatine layers of $4 \%$ and $5 \%$ concentration is investigated using a high speed camera with 300,000 fps. We analyze differences in the jetting behavior caused by differently prepared transfer layers and the laser fluence. We assume that the velocity of a first, fast jet is a key parameter to control the viability of cells and precision of positioning. In comparison to a single gelatine layer a double-layer prepared from 5\% gelatine coated with cell containing medium resulted in high cell survival rate and good precision.
\end{abstract}

DOI: $10.2961 / \mathrm{jlmn} .2016 .02 .0010$

Keywords: LIFT, eukaryotic cells, single cell transfer, hydrogel transfer layer, high speed camera

\section{Introduction}

Research aims to a new level in the field of artificial organs. Scientists claim that they are on the verge of a great breakthrough since the 1990s. But up to now only simple structures, like cartilage or thin skin have been successfully engineered[1;2]. Building organs remains challenging as they are more complex, e.g. the pancreas has several different functions including the production of digestive enzymes, the regulation of the blood sugar by insulin and glucagon secretion. For example, the Langerhans isles represent complex structures that enable the pancreas to play its vital role in blood sugar regulation. Before such in vivo like structures can be artificially recreated by bioprinting, their fundamentals have to be understood. Actually, such complex cellular structures cannot be produced in the laboratory.

A second example for a highly defined in vivo structure is the stem cell niche, which forms the stem cell's natural environment. Here a highly defined surrounding of stem cells allows the single stem cell to differentiate and renew itself. Different stem cell types live in spatially defined positions in an extracellular matrix. Stem cell renewal, apoptosis or differentiation is determined by cell-cell communication and location within the stem cell niche [3]. Being able to understand and control these differentiation dynamics would provide entire new possibilities in basic research, disease control, tissue repair and organ regeneration. Understanding of the stem cell dynamics therefore represents the key to unlock the stem cells' potential for medicine. As it is not yet feasible to position cells in a highly defined 3D environment in order to create such arti- ficial structures new built-up technologies have to be evolved.

To provide such artificial structures in vitro, a technology has to be developed that is capable of exactly positioning viable cells within a three dimensional environment similar or even identical to the extra cellular matrix of in vivo structures $[4 ; 5]$. Therefore printing technologies for living cells become more and more important $[6 ; 7]$. With the current state of the art bioprinting technology it is hardly feasible to transfer one single cell reliably [8] to a specific place. The Laser Induced Forward Transfer (LIFT) technology has been demonstrated to transfer biomolecules, hydrogels and cells over distances of up to $2 \mathrm{~mm}$ with high precision [9-12]. Especially the option to pick out a single cell from a population becomes a major advantage when the transfer laser beam is integrated into a microscope for optical analysis [13-15]. Morphological features or optical markers can be used to characterize and select each single cell before transferring.

To exploit the full potential of LIFT for the handling of living cells, a fundamental understanding of the process requirements and limitations is crucial. In recent years studies on the jet formation have shown how a jet is produced by the generation of a vapor bubble within the transfer layer [16]. During the transfer process first a fast jet develops which can be followed by a slower, but larger streamer thereafter [17-19]. In a preliminary study we found that the viability of cells is poor when only one single layer is applied on the transfer slide. Furthermore we observed fragmented cells on the receiver slide that indicate high shear forces during the LIFT process. If using a double layered transfer slide only intact cells where transferred which showed a better viability [20]. 
The aim of our investigation is to study the influence of the gelatine layer concentration on the jetting behavior. We observe the jet formation for $4 \%$ and $5 \%$ gelatine layer by high speed camera imaging and analyze the shape and speed of the jets. Afterwards we investigate the influence of a cell containing medium layer on top of the hydrogel. This second layer turned out to be very important to enhance the viability [20] for single cell transfer. Hence, with the twolayered transfer layer, a gentle transfer of living single cells is expected.

\section{Materials and Methods}

\subsection{LIFT Setup}

In this work a LIFT setup is used, which consists of two glass slides with cut edges (VWR, Germany) called transfer slide and receiver slide. The transfer slide carries the cells and enables the selecting of single cells under visual inspection. The receiver slide can be moved independently to build up a desired pattern. The positioning of the transfer and the receiver slides, as well as the firing of the laser can be program controlled as described elsewhere [15] in more detail.

The transfer is triggered by the beam of a UVmicrochip laser (Crylas FTSS355-Q3, $\lambda=355 \mathrm{~nm}, 1 \mathrm{~ns}$ pulse width, $10 \mu \mathrm{J}$ pulse energy) which is focused onto the transfer slide to a spot of $22 \mu \mathrm{m}$ in diameter for inducing the vapor bubble. Adjustment of pulse energy is performed by introducing optical attenuators with optical densities from 0.1 to 0.6 (Reflective Ø1/2" ND Filter ND01AND06A, Thorlabs). Higher optical densities are achieved by combining two neutral density filters.

The transfer slide consists of solid glass support, an absorption layer of $80 \mathrm{~nm}$ titanium, and a transfer layer of 60 $\mu \mathrm{m}$ gelatine (single layer slide). For cell transfer the cells can be embedded in the gelatine layer, or the gelatine layer can be coated with an additional cell containing medium (Fig. 1). The transfer slides are cleaned before coating with $2 \%$ Hellmanex II (Hellma GmbH \& Co. KG, Germany) at $37{ }^{\circ} \mathrm{C}$ for 30 minutes, washed with demineralized water, dried at $60{ }^{\circ} \mathrm{C}$ in the heating cabinet and sterilized with $70 \%$ ethanol. Two different ways of preparing the transfer layer are being compared:

1. Single layer, the hydrogel is evenly spread onto a titanium coated glass slide by a blade coater (BYK-Gardner, USA) which results in a layer thickness of $60 \mu \mathrm{m}$ (Fig.1 A). Two different gelatine concentrations $(4 \%$ and $5 \%$ gelatine) are used as hydrogel.

2. Double layer, a layer of cell containing medium is added to a transfer slide, which has already been coated with 5\% cell-free gelatine (Fig.1 B).

The receiver slides are coated with Matrige $\mathrm{l}^{\mathrm{TM}}$ of 100 $\mu \mathrm{m}$ as a damping layer, layer thickness was controlled by using a wire bar coater.

\section{A. Single-layered transfer system}

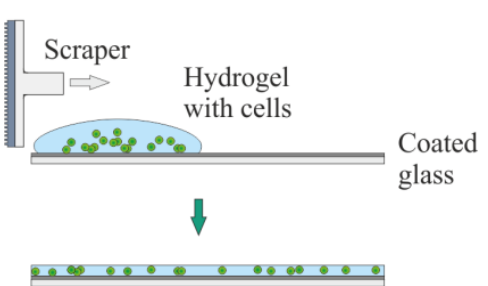

B. Double-layered transfer system

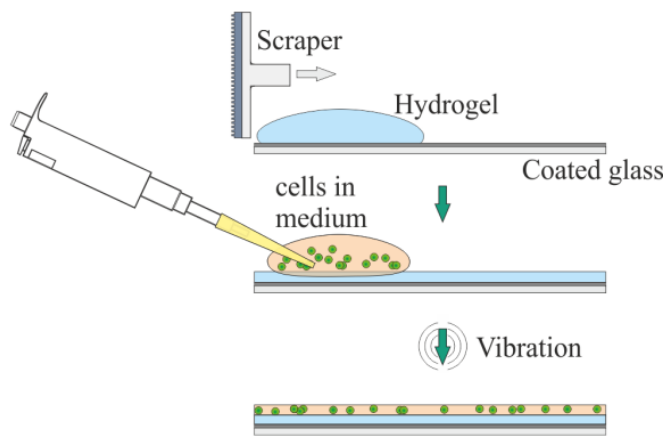

Fig.1 Preparation of the transfer slide. A: Single-layered transfer layer consisting of a hydrogel containing cells. B: Two-layered transfer layer consisting of a hydrogellayer and a cell-containing layer

\subsection{Preparation of slides with $\mathrm{CHO}$ cells}

For cell transfer $\mathrm{CHO}$ cells are grown in a Modified Dulbecco's Medium with a final concentration of $10 \%$ of fetal bovine serum. For transfer slide preparation $300 \mu$ of $5 \%$ gelatine (Sigma Aldrich, Germany) at $30^{\circ} \mathrm{C}$ are coated on a titanium coated glass slide with blade coater. The gel is incubated at room temperature. The cell containing layer is prepared from 30,000 cells suspended in $1 \mathrm{ml}$ medium and poured onto the coated slide. After an incubation time of 3 minutes, excess medium is removed from the slide.

\subsection{High-speed camera setup}

A high-speed camera (Fastcam SA5, Photron) with up to 300,000 frames per second, equivalent to a time resolution of $3.3 \mu \mathrm{s}$, is used for monitoring the emerging jet. Image acquisition is started automatically when the camera sensor detects any changes in a scene. A zoom objective (tele centric zoom objective 100, Optem) is used to adjust the magnification that the field of view in the vertical axis corresponds to the gap between the transfer and the receiver slide, which is approximately $1 \mathrm{~mm}$ in distance. Due to the optical quality of the objective and the pixel count of $320 \times 192$ a spatial resolution of about $5 \mu \mathrm{m}$ can be obtained. A home-made diode laser source $(809 \mathrm{~nm}, 30 \mathrm{~W})$ is used for back light illumination. The radiation is fed through a $400 \mu \mathrm{m}$ core fiber and collimated by a lens $\mathrm{f}=50$ $\mathrm{mm}$ focal length with diffusor plate $\left(50^{\circ}\right.$ Circle Pattern Diffuser ED1-C50, Thorlabs) to illuminate a spot of approximately $20 \mathrm{~mm}$ in diameter. Background light is suppressed by a laser line filter $809 \mathrm{~nm}$ in front of the camera objective (Fig.2)

For analyzing the data a script in Matlab ${ }^{\mathrm{TM}}$ was implemented that enables automatically detecting of the jet tip. The velocity is determined when the tip of a jet reaches a 
distance of approximately $0.7 \mathrm{~mm}$, the distance and time stamp from a frame next to that point is used for calculation. The length of the error bars is related to the uncertainty derived from the predecessor and the subsequent frame.

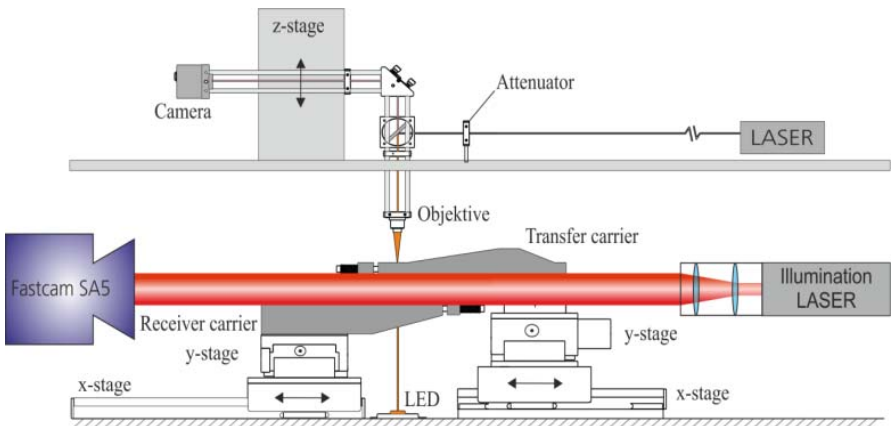

Fig.2 Sketch of LIFT Setup for high speed imaging, a Fastam SA5 (Photron) camera is used with back light illumination by a diode laser ( $809 \mathrm{~nm})$.

\section{Results and Discussion}

Different stages of the jet formation can be characterized for a laser fluence of $0.5 \mathrm{~J} / \mathrm{cm}^{2}$ to $3 \mathrm{~J} / \mathrm{cm}^{2}$. First, a fast jet regime can be described. For a fluence of $1.6 \mathrm{~J} / \mathrm{cm}^{2}$ about $3 \mu$ s after the LIFT pulse a narrow jet starts emerging from the surface of the transfer layer. For a gelatine concentration of $5 \%$ the fast jet arrives the receiver layer in $1 \mathrm{~mm}$ distance within $70 \mu \mathrm{s}$. After $20-40 \mu \mathrm{s}$ a second slower, but broader jet evolves. The slower jet arrives at the receiver slide after about $450 \mu$ s (Fig.3).
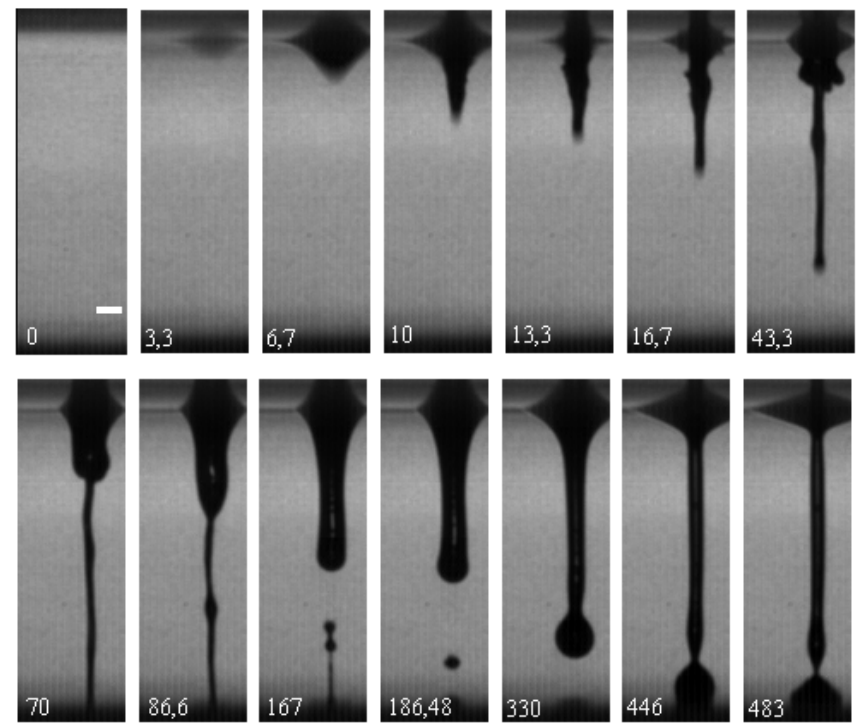

Fig.3 Single layer experiments, transfer of $5 \%$ gelatine at fluence of $1.6 \mathrm{~J} / \mathrm{cm}^{2}$, velocity of first jet $\sim 14 \mathrm{~m} / \mathrm{s}$; scale bar $100 \mu \mathrm{m}$, timescale in $\mu \mathrm{s}$.

If a lower concentration of $4 \%$ gelatine is used, we observe a fast jet and a slow jet too (Fig.4). The tip of the fast jet has already reached the receiver $6.7 \mu \mathrm{s}$ after the LIFT pulse, thus its speed is about $150 \mathrm{~m} / \mathrm{s}$ and roughly 10 -times higher than the velocity in case of $5 \%$ gelatine for the same fluence. A second, slower jet arises for $4 \%$ gelatine with a velocity of only $4.6 \mathrm{~m} / \mathrm{s}$ which is comparable to the layer of $5 \%$ gelatine.

As it can be seen from Fig. 4, the stability of the $4 \%$ gelatine jet is poor compared to a typically $5 \%$ gelatine jet depicted in Fig.3. The images taken at $10 \mu \mathrm{s}, 13.3 \mu \mathrm{s}$ and $16.7 \mu \mathrm{s}$ imply that a part of the transferred material bounces back and forth when hitting the receiver's surface. Thus we chose a gelatine concentration of $5 \%$ for the experiments on the two-layer structure.
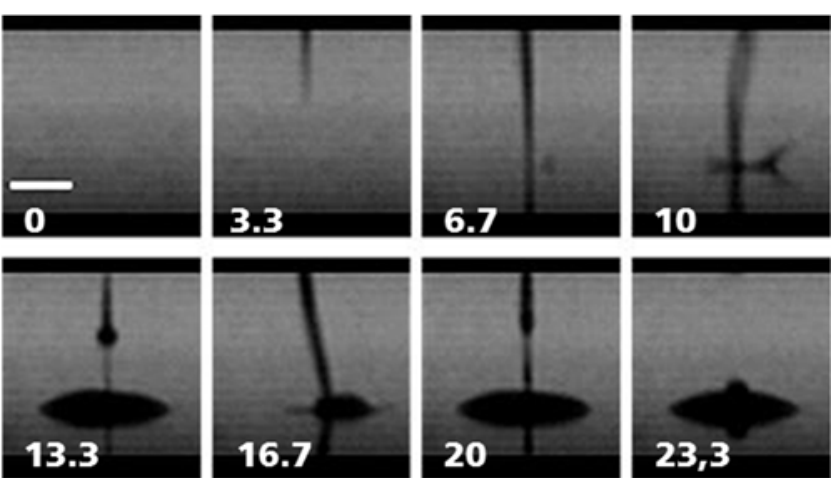

Fig.4 Single layer experiments, transfer of $4 \%$ gelatine at a fluence of $1.6 \mathrm{~J} / \mathrm{cm}^{2}$, velocity of first jet $\sim 150 \mathrm{~m} / \mathrm{s}$; scale bar $300 \mu \mathrm{m}$, timescale in $\mu \mathrm{s}$.

The dependency of the jet velocity on fluence was studied on a $5 \%$ gelatine layer. The velocities of the first and the second jet increase in a range from the threshold for jet formation (roughly $0.5 \mathrm{~J} / \mathrm{cm}^{2}$ ) to values near $3 \mathrm{~J} / \mathrm{cm}^{2}$. Here a clear difference between the first and the second jet can be observed. While the velocity of the first jet increases virtually linear, the velocity of the second jet saturates for a fluence above $1 \mathrm{~J} / \mathrm{cm}^{2}$. Thus the difference in velocity, and therefore in kinetic energy, is growing for high fluence (Fig.5) for $5 \%$ gelatine.

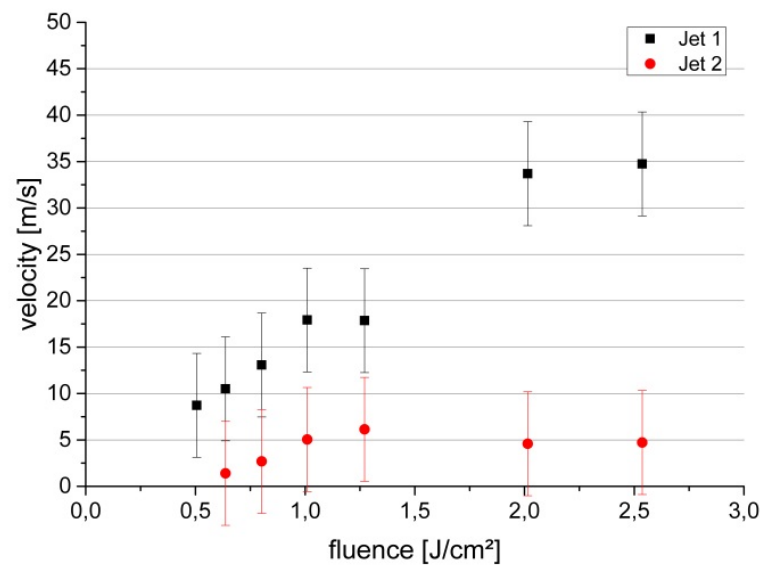

Fig.5 Jetting velocity for fast (jet1) and slow (jet2) component depending on fluence, single layer of $5 \%$ gelatine. 
When a 5\% gelatine layer is coated with the cell containing medium layer we observe only one single jet for a fluence up to $0.8 \mathrm{~J} / \mathrm{cm}^{3}$ (see Fig.6). The second jet only develops when a fluence of above $1 \mathrm{~J} / \mathrm{cm}^{2}$ is applied. At a relatively low fluence of $0.8 \mathrm{~J} / \mathrm{cm}^{2}$ the velocity of the only one jet is of about $40 \mathrm{~m} / \mathrm{s}$, this value is between the velocity of $150 \mathrm{~m} / \mathrm{s}$ for the $4 \%$ layer and $14 \mathrm{~m} / \mathrm{s}$ for the $5 \%$ layer obtained at $1.6 \mathrm{~J} / \mathrm{cm}^{2}$.
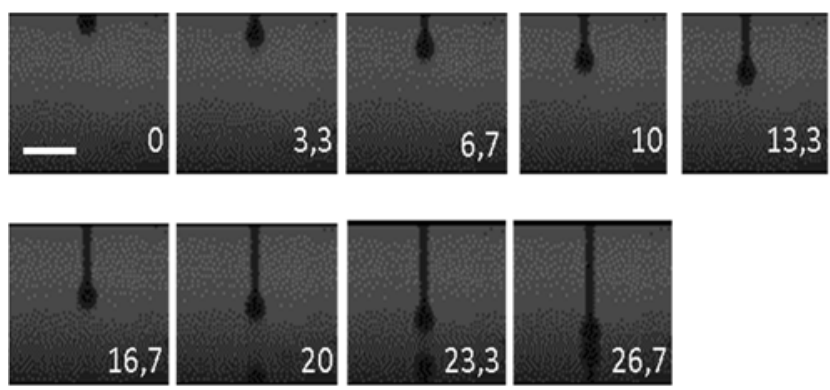

Fig.6: Double layer experiments, transfer of $5 \%$ gelatine coated with medium, fluence of $0.8 \mathrm{~J} / \mathrm{cm}^{2}$, velocity of first jet $\sim 40 \mathrm{~m} / \mathrm{s}$; scale bar $300 \mu \mathrm{m}$, timescale in $\mu \mathrm{s}$.

The occurrence of a first and potentially a second jet is already described in literature. In recent years studies have shown that the laser pulse generates a vapor bubble within the transfer layer. In the so called jetting regime [21] the laser fluence is high enough that a first thin, fast jet emerges due to the high pressure that is built up above the bubbles upper pole. Simultaneously a counter jet runs back into the vapor pocket. In some works the emerging of a thicker, slower jet is described following the first thin one [21-23]. According to investigations on film-free laser printing of a liquid $[17 ; 24]$ the second jet is caused by the bubble dynamics. As the counter jet traverses the collapsing vapor bubble it forces the bubble into a toroidal shape. Furthermore, when the counter jet breaks through the bubble's lower border, a new smaller bubble is generated. The reexpansion of the toroidal pocket generates a ring of high pressure, pushing the liquid away from the free surface. Thus a second cylindrical jet arises surrounding the first needle jet and propagates into the same direction.

Since it was found in preliminary experiments [15] that cell survival and printing accuracy deteriorate for fluence above $1.8 \mathrm{~J} / \mathrm{cm}^{2}$, our hypothesis is, that the velocity of the first (or only) jet determines the viability and survival rate of the transferred cells. If the second, slow jet would be dominating, above a certain threshold (e.g. $1.2 \mathrm{~J} / \mathrm{cm}^{2}$ according to Fig. 5) no influence would be expected. Nevertheless, the second jet seems to carry a larger amount of material than the first. One explanation for that observation could be, that the cells are carried within the first jet, and the kinetic energy of the jet determine the fate of cells. On the other hand, it is observed that the width and the length of the second jet depends on fluence or pulse energy. Therefore the impact of the bulk mass could affect the survival of the cells, too. This aspect is not covered by the simple velocity data shown in Fig. 5. Actually, we do not have enough data to confirm one or another hypothesis.

For the transfer of living cells it seems to be crucial that the velocity of the first jet is clearly below $200 \mathrm{~m} / \mathrm{s}$. When using the double layer technique with $5 \%$ gelatine and coating with cell containing medium stable single cell transfer with viable cells can be obtained. As an example for such a cell transfer single $\mathrm{CHO}$ cells are transferred onto a Matrigel $^{\mathrm{TM}}$ layer (Fig.7). The transferred cells showed no fragments or disintegration $10 \mathrm{~min}$. after transfer, and good proliferation could be observed after 5 days incubation.
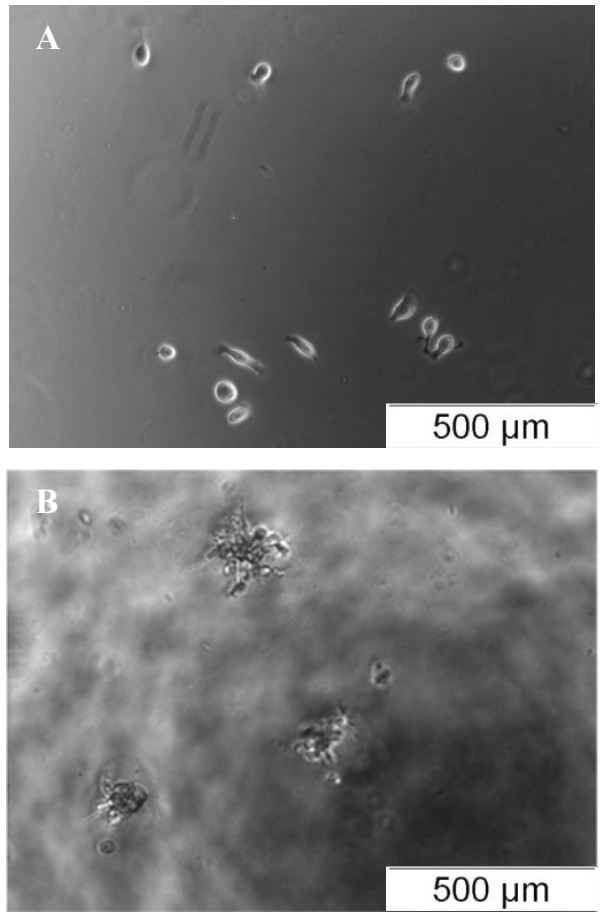

Fig.7A CHO-cells transferred with a fluence of $0.8 \mathrm{~J} / \mathrm{cm}^{2}$; $\mathrm{A}$ : single $\mathrm{CHO}$ cells $10 \mathrm{~min}$. after transfer from a $5 \%$ gelatine double layer slide; $\mathbf{B}$ Cell proliferation after 5 days incubation at $37{ }^{\circ} \mathrm{C}$ and $5 \% \mathrm{CO}_{2}$.

\section{Conclusion}

Our investigations reveal that changing the concentration of the gelatine layer from $4 \%$ to $5 \%$ has a strong effect on jet formation. Monitoring the jetting process by high speed imaging shows, that the velocity of a first, fast jet is dependent on the concentration of the gelatine layer and the laser fluence. A second, slower jet evolves when the fluence exceeds a certain threshold, e.g. $0.6 \mathrm{~J} / \mathrm{cm}^{2}$ for $5 \%$ gelatine layer of $60 \mu \mathrm{m}$ thickness.

If cell medium is added on top of the $5 \%$ gelatine layer the jetting characteristics appears to be between the $5 \%$ and $4 \%$ gelatine single layer preparations. This may be explained by a partial dilution of the $5 \%$ gelatine by soak up of cell medium. From these experiments we conclude, that small differences, e.g. changing the gelatine concentration 
between $4 \%$ and $5 \%$, will have a strong effect on the jetting behavior. From experiments on cell transfer and the velocity measurement for the first and second jet we conclude, that the velocity of the first jet determines the viability of transferred cells. From our experience, a 5\% gelatine layer coated with cell containing medium gives good results in respect to cell viability.

Nevertheless, the influence of the coating parameters have to be studied in more detail. Small variations in the preparation of the layers and the handling, e.g. storage time before use, will influence the resulting gelatine concentration and become important to establish a stable jetting regime.

\section{Acknowledgments}

This work was performed in the framework of the project "ComPASS", which was funded by the Federal Ministry of Education and Research, Germany. Special thanks go to the Max Planck Institute for Molecular Biomedicine to Ralf Adams, Gabriele Bixel and Khrievono Khiki for the collaboration.

\section{References}

[1] D. J. Mooney, L. Cima, R. Langer, L. Johnson, L. K. Hansen, D. E. Ingber and J. P. Vacant: MRS Proc., 252, (1991) 345.

[2] D. W. Hutmacher: Biomaterials, 24, (2000) 2529.

[3] K. A. Moore and I. R. Lemischka: Science, 311, (2006) 1880.

[4] V. Mironov, V. Kasyanov, C. Drake and R. R. Markwald: Regen. Med., 1, (2008) 93.

[5] V. Mironov, T. Trusk, V. Kasyanov, S. Little, R. Swaja and R. Markwald: Biofabrication, 2, (2009) 022001 .

[6] R. Narayan, T. Boland, Y. Lee: "Printed Biomaterials",(Springer NY, 2009) ISBN 978-3-642-00169-7.

[7] B. Guillotin and F. Guillemot: Trends Biotechnol., 4, (2011) 183.

[8] A. R. Liberski, J. T. Delaney and U. S. Schubert: ACS Comb. Sci., 2, (2011) 190.

[9] M. Gruene, A. Deiwick, L. Koch, S. Schlie, C. Unger, N. Hofmann, I. Bernemann, B. Glasmacher and B. Chichkov: Tissue Eng. Part C, 17, (2011) 79.

[10] N. R. Schiele, D. T. Corr, Y. Huang, N. Abdul Raof, Y. Xie and D. B. Chrisey: Biofabrication, 3, (2010) 032001 .

[11] F. Guillemot, A. Souquet, S. Catros, B. Guillotin, J. Lopez, M. Faucon, B. Pippenger, R. Bareille, M. Rémy, S. Bellance, P. Chabassier, J. C. Fricain and J. Amédée: Acta Biomater., 7, (2010) 2494.

[12] M. Colina, M. Duocastella, J. M. Fernández-Pradas, P. Serra and J. L. Morenza: J. Appl. Phys. 8, (2006) 084909.

[13] J. A. Barron, D. B. Krizman, B. R. Ringeisen: Ann. Biomed. Eng. 33, (2005) 121.
[14] A. Ovsianikov, M. Gruene, M. Pflaum, L. Koch, F. Maiorana, M. Wilhelmi, A. Haverich and B. Chichkov: Biofabrication, 2, (2010) 014104.

[15] D. Riester, A. Özmert and M. Wehner: J. Laser Micro/Nanoengin., 2, (2014) 93.

[16] Chen, Ross C C, Y. T. Yu, K. W. Su, J. F. Chen and Y. F. Chen: Opt. Express, 1, (2013) 445.

[17] A. Patrascioiu, J. M. Fernández-Pradas, A. PallaPapavlu, J. L. Morenza and P. Serra: Microfluid. Nanofluid., 1-2, (2014) 55.

[18] S. L. Rowe, S. Lee and J. P. Stegemann: Acta Biomater., 1, (2007) 59.

[19] A. I. Kuznetsov, C. Unger, J. Koch and B. N. Chichkov: Appl. Phys. A, 3, (2012) 479.

[20] D. Riester, "Ortsselektives, präzises Laserdrucken von Biomaterialien und Zellen", (Apprimus Verl., Aachen, 2015) ISBN 978-3-86359-313-1

[21] M. Ali, E. Pages, A. Ducom, A. Fontaine and F. Guillemot: Biofabrication, 4, (2014) 045001.

[22] C. Unger, M. Gruene, L. Koch, J. Koch, B.N. Chichkov: Appl. Phys. A, 103, (2010) 271.

[23] J. Yan, Y. Huang, C. Xu, D.B. Chrisey: J. Appl. Phys., 112, (2012) 083105

[24] A. Patrascioiu, J. M. Fernández-Pradas, J. L. Morenza and P. Serra: Appl. Surf. Sci., 302, (2014) 303. 